\title{
A EDUCAÇÃO AMBIENTAL NO ENSINO BẢSICO ATRAVÉS DAS INTERVENÇÕES DO PIBID E AS CONTRIBUIÇÕES DO PROGRAMA PARA A FORMAÇÃO DOCENTE
}

Edinalva Alves Vital dos Santos ${ }^{1}$

Maria Tatianny de Oliveira Vasconcelos ${ }^{2}$

Resumo: Esta pesquisa teve como objetivo analisar as práticas pedagógicas desenvolvidas nas aulas de ciências, com ênfase na Educação Ambiental, e as contribuições do PIBID na formação docente. As atividades foram realizadas com alunos do $7^{\circ}$ e $8^{\circ}$ anos da Escola Estadual de Ensino Fundamental André Vidal de Negreiros, na cidade de Cuité - PB, entre os anos de 2015 e 2016. Diversas ações foram realizadas, a exemplo de trilhas ecológicas, práticas de arborização na escola, construção de uma estufa ecológica e aplicação de jogos didáticos. Os exercícios tiveram resultados positivos, auxiliando o trabalho do professor, facilitando a aprendizagem dos alunos e, sobretudo, dando suporte para a carreira das bolsistas em formação.

Palavras-chave: Didática Escolar; Conservação e Preservação Ambiental; Ludicidade; Docência Compartilhada; Aprendizagem Significativa.

1Universidade Federal da Paraíba, Centro de Ciências Agrárias. E-mail: ednalva.avs@gmail.com.

¿Universidade Federal de Campina Grande Centro de Educação e Saúde. E-mail: tatiannymcoliveira@gmail.com. 


\section{Introdução}

O Programa Institucional de Bolsa de Iniciação à Docência (PIBID), criado em 2007, pela portaria ํo. 096/2013, na Lei ํo. 12.796/2013, e no Decreto ํo. 7.219/2010 tem por objetivo promover a iniciação à docência por meio do apoio aos cursos de licenciatura, através da elaboração e aprovação de projetos que tragam melhorias para a formação de professores e para a educação básica (HARDOIN; SILVA; CHAVES, 2017). Neste mesmo contexto Silva e Nunes (2016, p. 92 - "grifo dos autores") especificam os objetivos do PIBID na mesma vertente abordada pelos autores supracitados.

Tem como principais objetivos encurtar a distância existente entre Educação Básica e Instituições de Ensino Supe rior, e consequentemente trabalhar a dicotomia existente entre teoria e prática; promover a valorização do magistério; trabalhar com a vertente dos egressos dos cursos de licenciatura, que, a partir do programa, retornam às Instituições de Ensino Superior (IES); valorizar a escola pública como espaço de produção de conhecimento; e inserir o licenciando diretamente na educação básica, que é o seu locus de trabalho.

A participação dos alunos de licenciatura nos projetos de iniciação à docência tem demonstrado relevância frente à realidade dos processos educativos escolares do Ensino Básico nas escolas públicas, e surge como uma capacitação antecipada da formação, em que os alunos têm a oportunidade de se inserir no meio acadêmico, vivenciar desafios e adquirir percepções acerca da profissão.

Antes da execução do PIBID nas IES, os alunos dos cursos de licenciatura tinham contato com as escolas apenas através dos estágios, mas hoje a realidade dos cursos que se encaixam no programa é diferente, os discentes, já no segundo período do curso, têm a oportunidade de se submeter à seleção para participar do programa e iniciar os trabalhos nas escolas. Essa oportunidade demonstra-se importante para que os licenciandos desenvolvam habilidades de atuação em sala de aula.

$\mathrm{Na}$ realidade proposta pelo PIBID, os professores em formação, a partir do II semestre, podem atuar como bolsista de Iniciação a Docência (ID) em tal programa.

O que é um ponto de grande importância na formação deste futuro professor, pois, desde cedo, já é posto a conhecer o chão escolar, e assim interagir e atuar de forma crítica e transformadora frente aos impasses e problemas educacionais (SILVA; CARVALHO, 2015, p. 11). 
possibilidade de os alunos praticarem a teoria que vem sendo construída na academia. Esta prática, segundo os autores, desenvolve o senso crítico para os alunos compreenderem o elo entre teoria e prática. Os autores ainda enfatizam a importância de estabelecer este contato direto com a realidade escolar, para que os bolsistas comecem a adquirir competências de acordo com o planejamento da escola.

A posição dos autores remete aos confrontos de realidade, do que se idealiza para o processo de ensino-aprendizagem nas Universidades, enquanto alunos em formação, e a prática escolar vivenciada em salas de aula fora do âmbito universitário. E o PIBID proporciona uma ponte de ligação para conhecer a diferença existente nestes dois âmbitos de ensino e capacitar os acadêmicos a atuarem de acordo com a veracidade dos fatos.

Portanto, a criação do PIBID foi importante, uma vez que quebra os paradigmas e as frustrações de profissionais que conheciam duas vertentes, isto é, o ensino visto na teoria, e ensino vivenciado na prática, para o ensino básico, quando, muitas vezes, a teoria não condiz coma veracidade enfrentada em sala de aula. Sendo assim, o programa proporciona ao aluno em formação conhecer não apenas a teoria didática pedagógica, mas também a realidade da educação básica.

A teoria é importante para o processo de formação, como afirma Melo e Carvalho (2017, p.466): "a formação inicial caracteriza-se como um espaço acadêmico no qual o licenciando constrói a sua identidade profissional e adquire saberes da docência". Os autores revelam que, ao longo da história, problemas vêm sendo observados na formação dos professores que apresentam dificuldades de

Construção e domínios sólidos dos saberes da docência (saberes disciplinares e curriculares, saberes pedagógicos e saberes da experiência profissional), a unicidade entre teoria e prática e a intervenção na prática social e pedagógica, entre outros (MELO; CARVALHO, 2017, p.466).

E o PIBID, neste aspecto, tenta solucionar esses problemas, colocando alunos de licenciatura dentro deste cenário, para que os mesmos tenham uma participação ativa na construção da educação.

Partindo dos pressupostos que o PIBID representa para a formação de professores, o presente trabalho tem por objetivo analisar as práticas desenvolvidas com ênfase na Educação Ambiental, nas aulas de Ciências, e as contribuições do programa de ID para a formação docente. 


\section{Metodologia}

O trabalho trata sobre um relato de experiência, com abordagem descritiva seguindo os critérios de Gil (2008) sobre as vivências das autoras no PIBID-subprojeto de Biologia, no qual desenvolveram várias atividades pedagógicas nas aulas de ciências, com turmas de $7^{\circ}$ e $8^{\circ}$ anos do Ensino Fundamental, na Escola Estadual de Ensino Fundamental André Vidal de Negreiros, na cidade de Cuité-PB.

Foram realizadas diversas atividades voltadas, principalmente, para Educação Ambiental. Dentre elas, incluem exposições de conteúdos teóricos, saídas de campo para uma lagoa no centro da cidade, trilhas ecológicas interpretativas em uma área remanescente de Caatinga, coleta e reutilização de garrafas PET para construção de uma estufa sustentável, arborização da escola com espécies nativas da Caatinga, além de atividades lúdicas.

As produções destas atividades ocorreram de Janeiro de 2015 a Julho de 2016. A análise dos resultados é de caráter qualitativo, e a discussão e conclusão trouxeram respaldos e ponderações embasadas na literatura especializada.

\section{Resultados e discussão}

\section{Atividades desenvolvidas}

Durante o percurso das alunas no programa, juntamente com outros estagiários do PIBID, diversas atividades foram realizadas com turmas de $7^{\circ} \mathrm{e}$ $8^{\circ}$ anos do Ensino Fundamental, sob orientação do coordenador do subprojeto Biologia e da professora supervisora, trabalhando a Educação Ambiental de forma transversal às disciplinas.

Neste aspecto, pensando os problemas ambientais que estamos enfrentando e como a Educação ambiental se faz necessária para formar cidadãos críticos sobre as dificuldades ecossistêmicas. Foram elucidadas as problemáticas ambientais da realidade dos alunos, para que os mesmos compreendessem a necessidade de mudar os hábitos e tornarem-se seres humanos responsáveis e defensores da natureza. De acordo com Freitas Filho et al. (2015, p.2), "as estratégias de ensino utilizadas pelos docentes, devem ser capazes de sensibilizar e de envolver os estudantes ao ofício do aprendizado, deixando claro o papel que lhe cabe".

Para pontuar melhor as atividades, decidiu-se trabalhar a importância da preservação das nascentes e dos corpos d'água, principalmente, porque vivemos em uma região semi-árida onde os ciclos de chuvas são cada vez mais curtos e irregulares, e a situação da população sobre a escassez e qualidade da água é preocupante. Pensando nisto, os Bolsistas levaram a turma de $8^{\circ}$ ano para conhecer de perto a situação ambiental de uma lagoa no centro da cidade, que se encontra imprópria para o uso humano (Figura 1). 


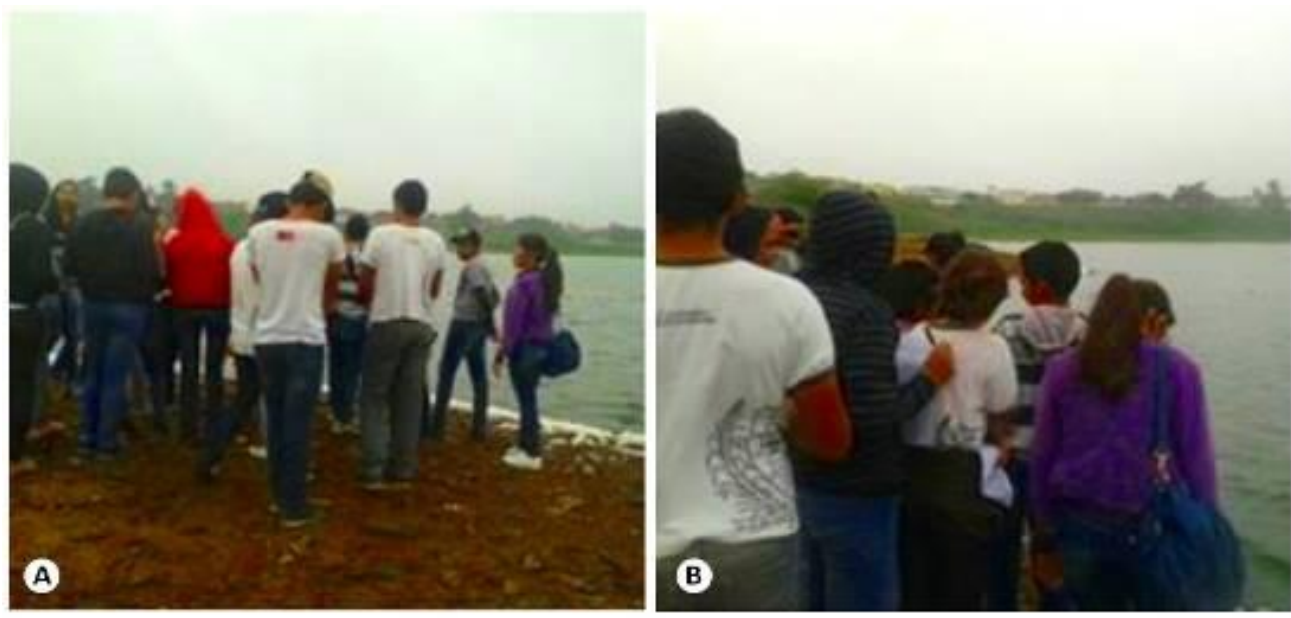

Figura 1: Visita dos Alunos do $8^{\circ}$ ano a Lagoa Bela Vista, situada no centro da cidade de Cuité-PB. Fonte: Dados da Pesquisa, 2016.

Os alunos puderam observar diversas irregularidades às margens da lagoa, como criações de bovinos e equinos, erosões, canais de esgotos urbanos e tubulação de efluentes domésticos que são lançados na lagoa. Estes impactos antrópicos já foram relatados por Santos e Silva (2017) e Galdino (2015), os quais concluíram que o crescimento urbano sem planejamento de tratamento sanitário foi à principal causa de degradação da Lagoa.

Todas estas questões foram abordadas junto aos alunos, para que os mesmos compreendessem que as ações de desrespeito contra a natureza a degradam e colocam em risco a qualidade de vida das pessoas que dependem dos recursos naturais e, principalmente, do recurso hídrico (reservas de água), uma vez que ela é de grande valor à vida.

Então, as bolsistas buscaram sensibilizar os estudantes através desta visita de campo à lagoa, para mostrar a situação ambiental em que eles estão inseridos, e motivá-los a buscarem alternativas de conscientização ambiental e preservação das espécies. As excursões são importantes para os alunos, pois, através da observação do campo de estudo, é possível fazer uma associação das abordagens teóricas com as cotidianas. Estas medidas de conservação vão de acordo com Lima e Braga (2014, p. 1346), quando enfatizam que

O trabalho de campo surge como um recurso importante para se compreender de forma mais ampla a relação existente entre o espaço vivido e as informações obtidas em sala de aula, fazendo com que o aluno possa ter um melhor aproveitamento do conteúdo aprendido em sala de aula, tendo como objetivo principal familiarizá-lo com os aspectos físicos e naturais e com as atividades humanas relacionadas ao uso da terra, percebendo assim a identidade do lugar ou da comunidade. 
Os autores argumentam a relevância da Educação Ambiental, defendendo que esta deve assumir papel de destaque na educação formal, que se faz necessária para o desenvolvimento da consciência de preservação do meio ambiente por parte dos alunos. A esse respeito, conforme Silva et al. (2017, p.27), "para que a questão ambiental não fique restrita apenas no discurso é preciso promover ações que fomentem atitudes de respeito ao meio ambiente". Assim, a prática de campo vem como um complemento para teoria e suporte à compreensão dos estudantes.

Em outro momento, alunos do $7^{\circ}$ ano foram levados para participar de uma trilha ecológica no Horto Florestal da Universidade Federal de Campina Grande, Campus Cuité - PB, onde os mesmos tiveram a oportunidade de conhecer a fito fisionomia do Bioma Caatinga (Figura 2). Foi abordado o tema Caatinga e suas implicações ambientais, tendo em vista que os alunos estão inseridos neste domínio fitogeográfico e que, muitas vezes, desconhecem a vegetação da sua região, as suas problemáticas e a importância da sua conservação.
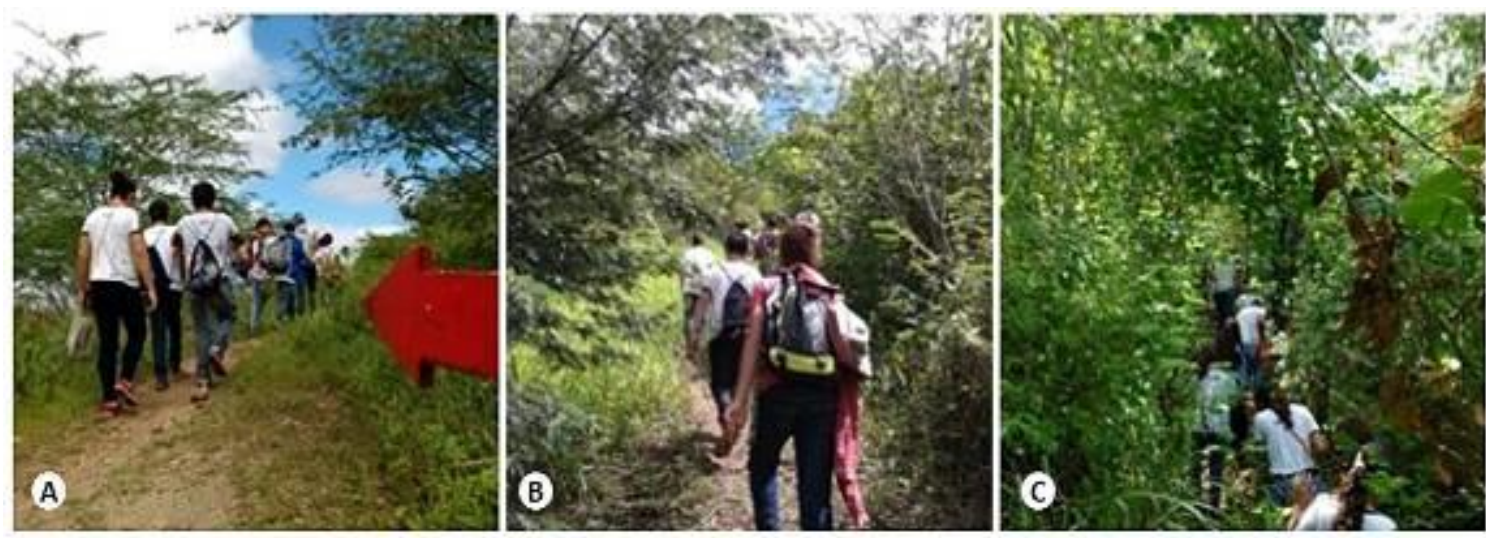

Figura 2: Trilhas interpretativas em uma área de Caatinga com alunos do $7^{\circ}$ Ano, Horto Florestal, CES-UFCG. Fonte: Dados da Pesquisa, 2016.

A Caatinga vem sofrendo um intenso processo de exploração que tem colocado em risco a sua biodiversidade, principalmente, pela caça ilegal, pelo desmatamento e pelas queimadas que vêm aumentando consideravelmente, também pela exposição dos solos, que vem desencadeando núcleos de desertificação. Alertar os alunos sobre essas questões através das trilhas, mostrarem como a importância da preservação se faz necessário para que eles se tornem pessoas conhecedoras dos impasses ambientais causados pelas ações antrópicas e, assim, integrar a criticidade em sua personalidade, tornando-os capazes de atuar e buscar mudanças que possam mitigar os problemas ambientais do seu entorno.

Durante as trilhas, os alunos tiveram a oportunidade de observar a paisagem de perto e ter um maior contato com o meio ambiente (Figura $3 \mathrm{C}$ ). Puderam aprimorar a visão do ecossistema através de lupas e binóculos (Figura 3. A-B-D), onde visualizaram animais, a exemplo de aves, pequenos Revbea, São Paulo, V. 13, № 4: 51-65, 2018. 
artrópodes, anfíbios, plantas e córregos, além de ouvir o som da natureza através do canto dos pássaros e o coaxar dos sapos. Este momento da trilha foi muito prazeroso uma vez que foi perceptível a interação dos alunos, o fascínio e encantamento que demonstraram pelo ambiente natural.

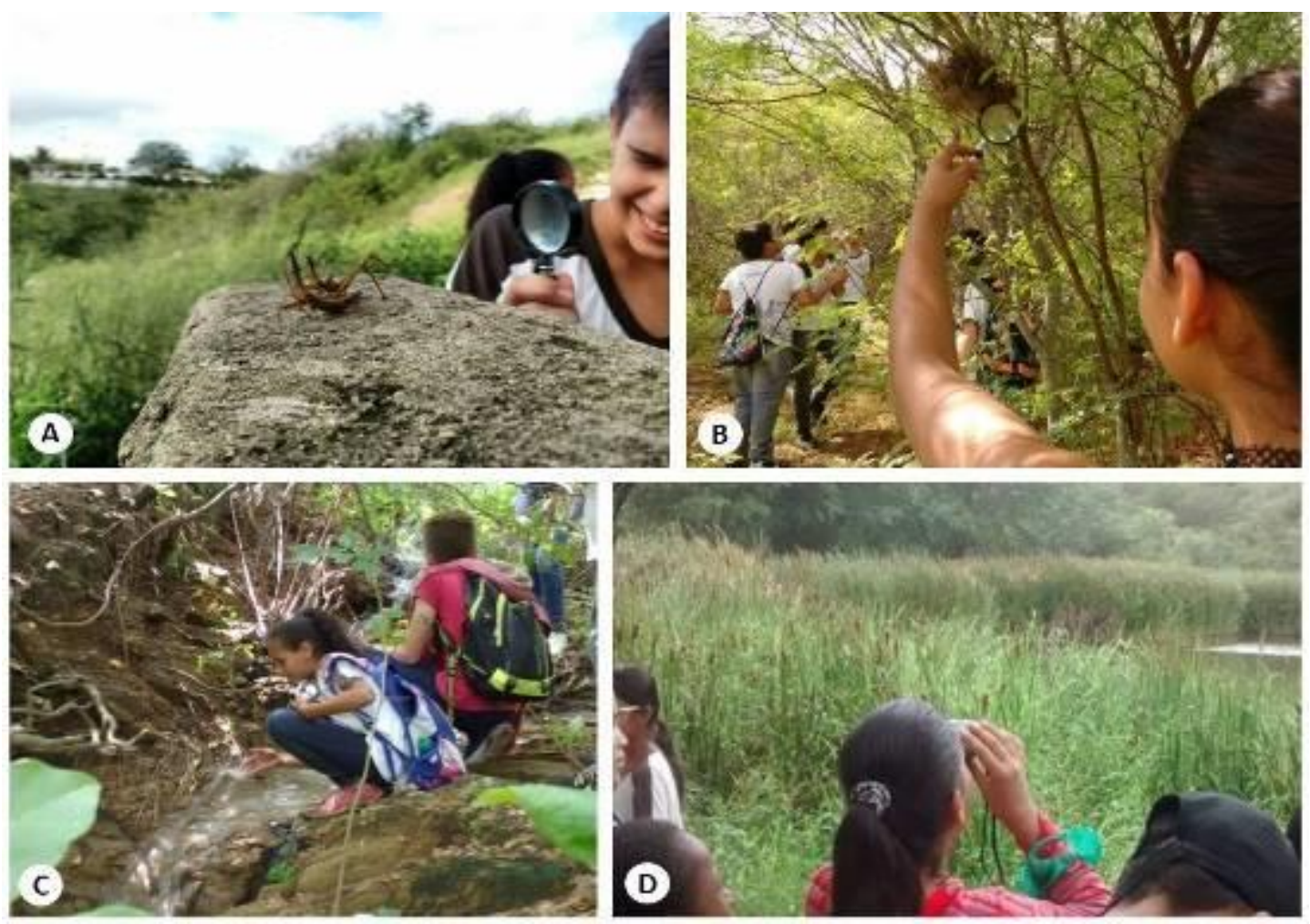

Figura 3 - Trilha Ecológica Interpretativa: A-B. Utilização de lupas para visualização de animais pelos alunos, C. Aluna apreciando a paisagem de um córrego. D. Observação do ambiente através de binóculos. Fonte: Dados da pesquisa, 2016.

De acordo com Eisenlohr (2013), as trilhas ecológicas desempenham um papel importante nas práticas de Educação Ambiental (EA), como espaços que vão além de ensinamentos, mas também como um momento que nos remete à reflexão de como pensamos e avaliamos nossa relação com a natureza. Machado e Abílio (2015), também em seu estudo, realizaram trilhas ecológicas como uma modalidade didática inovadora para valorização do Bioma Caatinga, com alunos do Ensino Fundamental, os quais participaram da atividade com bastante êxtase. Câmara e Lima (2017), ao realizarem trilhas interpretativas com alunos da Universidade Federal do Amazonas (UFAN), relataram que as trilhas foram eficazes na sensibilização dos estudantes com relação à primordialidade de se conservar as áreas florestais.

Após as trilhas interpretativas $e$ as abordagens teóricas sobre a caatinga, vendo a participação ativa dos alunos através de questionamentos e discussões sobre que medidas tomarem para mudar o cenário do Bioma, os bolsistas do PIBID, subprojeto de Biologia, resolveram, junto aos alunos, 
realizar uma prática de conservação das espécies nativas da nossa vegetação, através da arborização da Escola com espécies da Caatinga ideais para arborização (Figura 3). Os Alunos nesta prática foram agentes ativos durante as atividades, o que foi muito gratificante para os bolsistas, perceber que as mudanças nas práticas metodológicas tinham sido exitosas na mudança de comportamento dos alunos. Conforme Deus et al. (2014, p. 1):

A arborização de escolas pode ser um importante instrumento de Educação Ambiental, estimulando alunos e professores, para o conhecimento e valorização das espécies nativas e no exercício da cidadania e responsabilidade socioambiental, além de contribuir com o paisagismo e qualidade de vida do ambiente escolar.

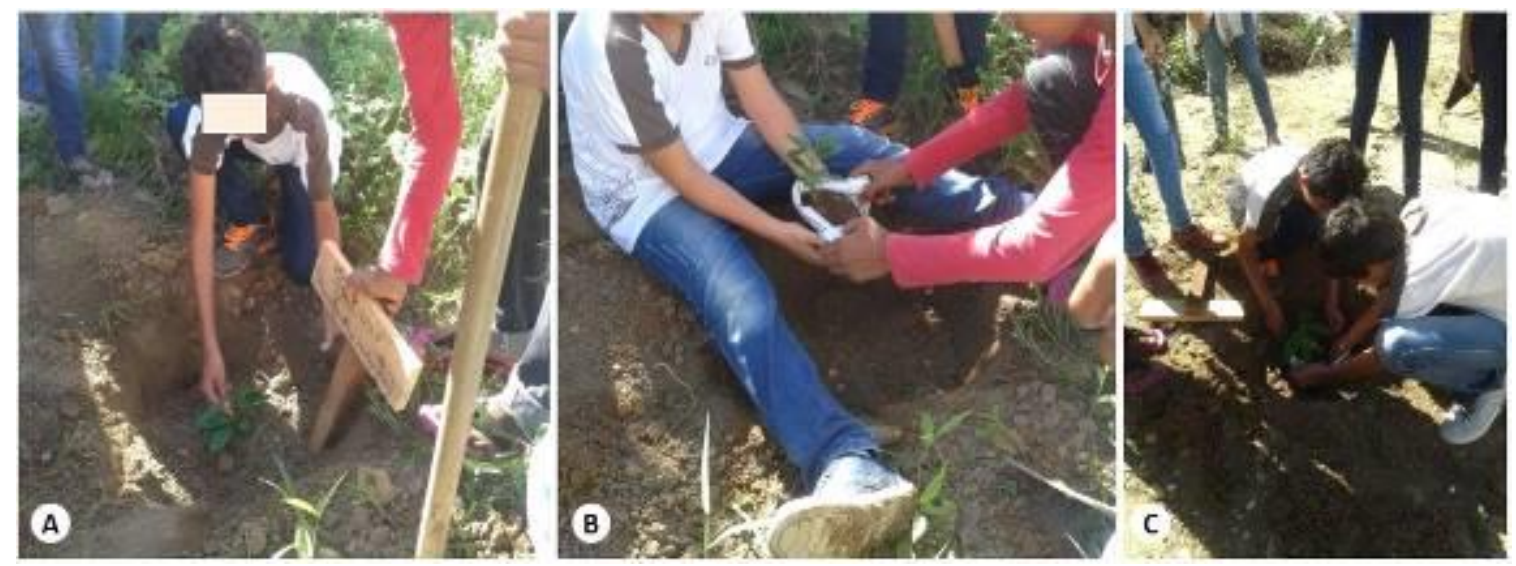

Figura 4: Prática de arborização da Escola, com alunos do $7^{\circ}$ ano, plantio de espécies nativas da Caatinga. Fonte: Dados da Pesquisa, 2016.

Pensando a questão do lixo, um tema bastante abordado nas escolas, os alunos do PIBID resolveram, após as explanações teóricas sobre a problemática, desenvolver práticas de reutilização de materiais PET visando a sua diminuição na cidade. Para tanto, as bolsistas do PIBID, juntamente com os alunos, passaram a arrecadar e a coletar garrafas pets em locais como restaurantes, casas residenciais, bares e outros lugares, a fim de obter um número considerável de garrafas que fossem suficientes para construir uma estufa. A estufa foi construída principalmente com garrafas pets, mas também foram usadas madeira de refugos e arames (Figura 5).

Foram utilizadas mais de mil (1.000) garrafas PET, uma quantidade considerável que poderia causar sérios problemas se descartados indevidamente no meio ambiente, tendo em vista que os materiais PET levam mais de 400 anos pra se decompor (MMA, 2018). 


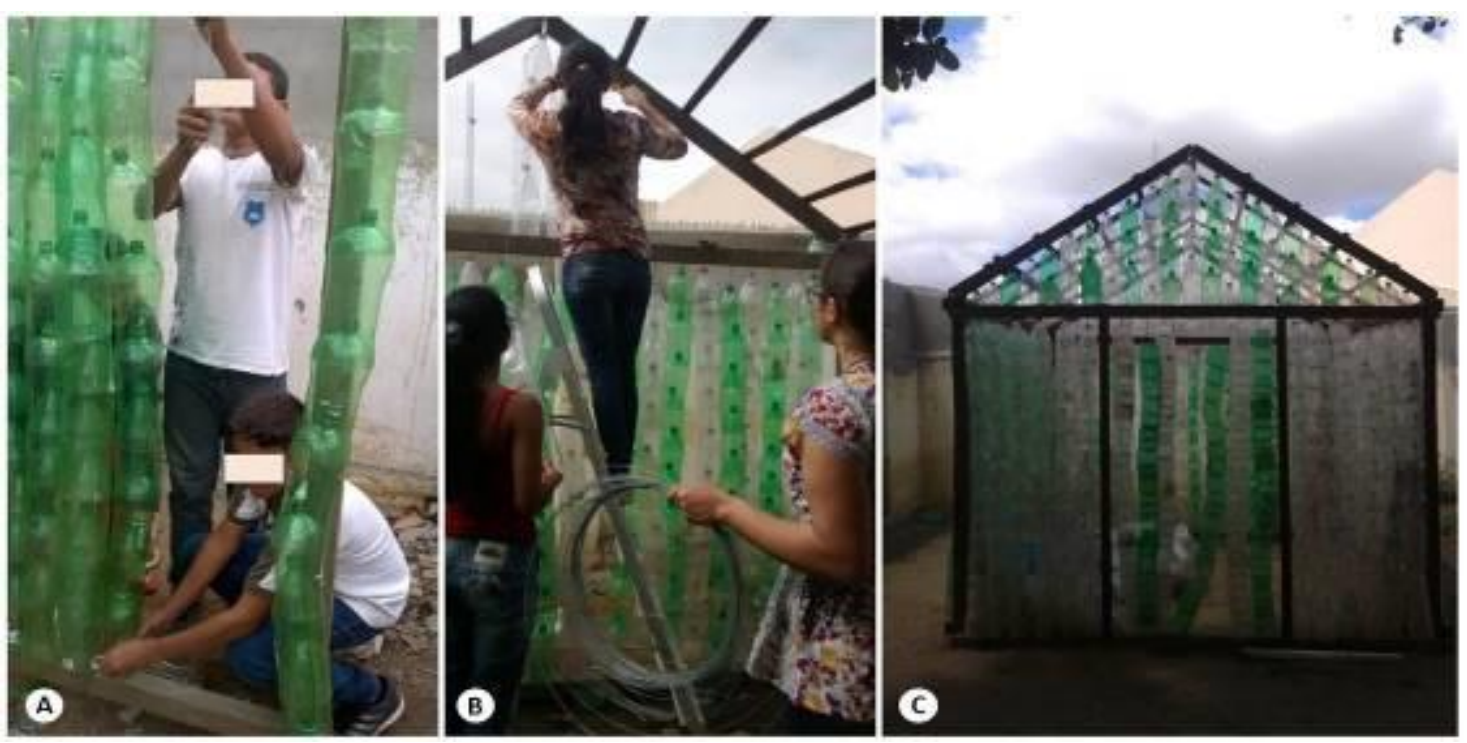

Figura 5: A-B. Participação dos Alunos e bolsistas do programa ID na construção da estufa, C. Estufa finalizada. Fonte: Dados da pesquisa, 2016.

O objetivo da construção da Estufa é trabalhar a educação ambiental através da conscientização do descarte incorreto do lixo, o consumismo exagerado, a reutilização de materiais pets e a estufa propriamente como espaço de práticas de EA.

A construção da estufa mostrou-se uma alternativa de baixo custo, econômica e sustentável, em que os alunos puderam perceber que ações simples como estas são relevantes e se fazem necessárias, sobretudo, partindo da sociedade, a fim de ajudar a natureza, o que não isenta e justifica a efetuação das políticas públicas sobre a temática do lixo e dos resíduos sólidos. Silva et al. (2015) já utilizaram garrafas PET como micro estufas, diferindo da construção aqui relatada, mas corroborando a utilização das garrafas pets como uso criativo, aproveitamento de um espaço e incentivo à produção de alimentos saudáveis por meio de hortas caseiras.

Muitas práticas de artesanato têm utilizado materiais PET, e isto tem mostrado como a criatividade pode contribuir na reutilização destes materiais, culminando o desenvolvimento sustentável e menor descarte de resíduos sólidos. Construções de móveis, a exemplo de pufes, mesas, cadeiras, sofá, poltronas etc., a partir de garrafas PET, foram apontadas por Correia (2010) como uma atividade rentável, além de apresentar uma solução ambientalmente correta para a destinação final das garrafas PET usada. Então, são estas experiências bem sucedidas que devem ser levadas para os alunos, para que os mesmos tomem para sua responsabilidade de cuidar do ambiente em que vivem.

Os subprojetos do PIBID trouxeram muitos impactos positivos para o âmbito escolar. As autonomias que os bolsistas tiveram em criar novas práticas pedagógicas, principalmente, voltadas para educação ambiental, contribuíram 
muito para a transformação e desenvolvimento de uma sociedade mais consciente e responsável. O trabalho de Alarcon e Bervian (2017) mostra o crescimento das produções cientificas dos bolsistas PIBID com ênfase nas práticas de EA trabalhadas nas instituições de ensino básico. Estes resultados mostram que a Educação Ambiental está sendo bem contextualizado na escola, o que torna a permanência do programa necessária e relevante para as instituições de Ensino Superior e Básico.

Além destas atividades práticas, os bolsistas aplicaram atividades lúdicas, a exemplos de jogos, a fim de proporcionar momentos de socialização entre os alunos e interação com os conteúdos abordados na disciplina de Ciências (Figura 6).
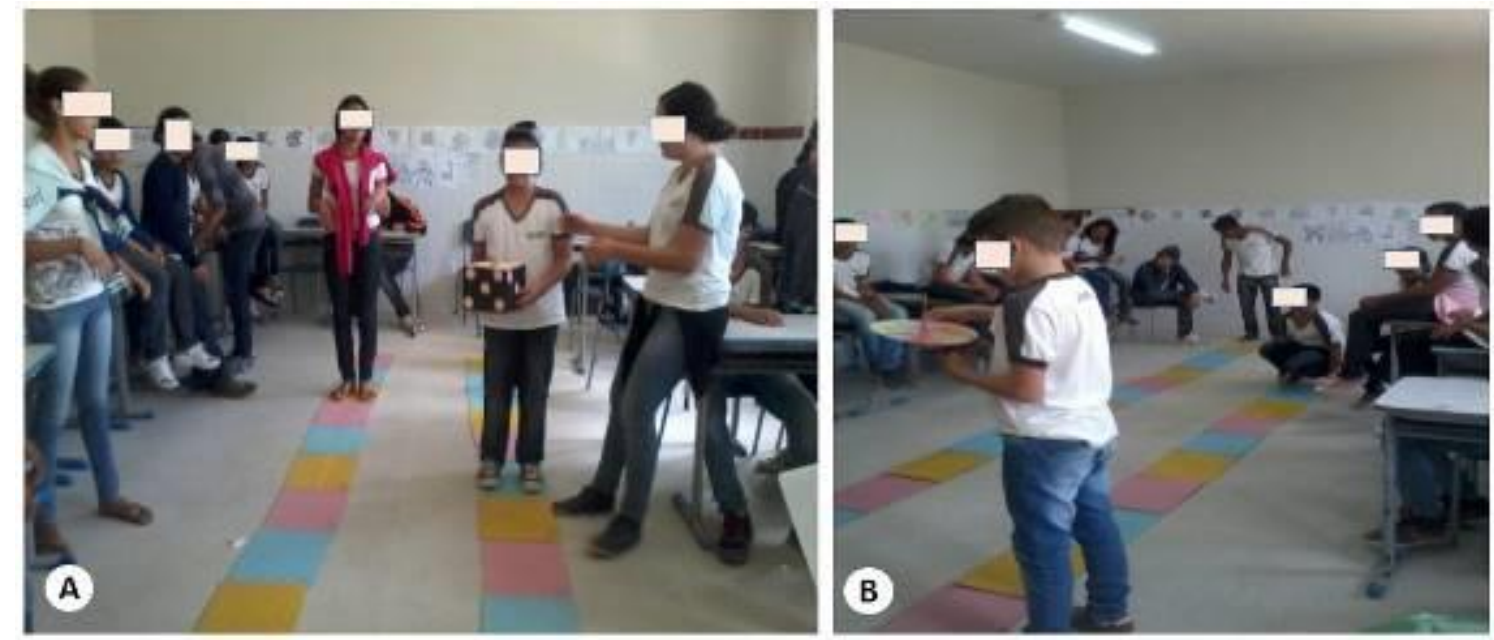

Figura 6: Aplicação de atividades lúdicas com os alunos do $7^{\circ} \mathrm{A}$, nas aulas de ciências.

Fonte: Dados da pesquisa, 2016.

Para Gonzaga et al. (2017, p. 3)

[...] os jogos são considerados um recurso ótimo do ponto de vista construtivista, promovendo a participação ativa do aluno no processo de construção do conhecimento, permitindo também o desenvolvimento intelectual e social desse aluno e proporcionando ao docente maior flexibilidade para contextualizar e promover a interlocução entre as diferentes áreas do conhecimento. 
A ludicidade favorece $o$ aluno a instigar o consciente, a construir um mapa conceitual abrangente que possa correlacionar com a prática interdisciplinar nas escolas. Assim, ativa partes cérebro que, muitas vezes, estão inutilizadas, a realizarem atividades constantes de raciocínio e interligação de conteúdos.

\section{O respaldo das práticas pedagógicas desenvolvidas pelo PIBID para a escola e para a formação docente}

Todas estas atividades descritas mostram o poder construtivo que o PIBID tem sobre os alunos de licenciatura, inserindo-os nas escolas e colocando-os como agentes de desenvolvimento de práticas pedagógicas. Mostra como o programa oferece aos alunos em formação a liberdade de inventar e se reinventar no campo de ensino. Esta oportunidade garantiu ao licenciando (a) construir concepções sobre quais as práticas metodológicas de ensino são pertinentes a cada situação, quais são desnecessárias e como ponderar e ministrar a teoria e a prática como facilitadoras da aprendizagem dos alunos.

Estas vivências proporcionaram a construção de experiências sobre o contexto escolar, preparando-os através das atividades realizadas, para que a partir de cada situação, possam aprimorar sua atuação, e, aos poucos, possam ganhar habilidades e competências para exercerem seus deveres como profissionais da educação após o término de sua formação docente.

Para um professor recém-formado, seria mais difícil se inserir no âmbito escolar sem antes ter tido nenhum contato com este universo, do que um professor que durante a sua formação teve a oportunidade de participar ativamente no planejamento e execução das práticas pedagógicas que rege o ensino-aprendizagem no contexto escolar, e o PIBID trouxe a oportunidade de diminuir o tempo que o aluno leva a se inserir na escola, e esta conjunção foi decisiva na escolha para carreira de magistério, ao mesmo tempo em que ajudou na construção da personalidade docente a partir das experiências vividas, oferecendo ao graduando a oportunidade de se apropriar da realidade do trabalho do professor.

Verasztoe colaboradores et al. (2017, p. 558), numa abordagem sobre os impactos do PIBID na formação de licenciando egressos dos cursos das ciências naturais, concluíram que este:

É um programa que dá sentido ao processo de formação inicial docente, garantindo aos licenciandos uma vivencia prática da realidade escolar, a partir do planejamento e aplicação de atividades que unem a teoria e a prática, encurtando assim a distância entre a universidade e a escola.

Conforme Melo e Carvalho (2017, p. 466):

Revbea, São Paulo, V. 13, № 4: 51-65, 2018.

revista brasileira

educação ambiental 
Nesse cenário, a formação inicial representa um processo em que os professores, ao longo de suas trajetórias universitárias, cumprem todos os estudos e atividades necessárias ao fluxo curricular correspondente ao curso escolhido. Essa formação é de grande valor para o educador, pois através dela, o licenciando poderá aprender sobre o exercício da profissão, contribuindo assim, para o desenvolvimento de conhecimentos, competências e atitudes necessárias ao exercício da docência.

Além da sua importância na formação docente, o PIBID mostrou-se muito relevante na formação dos alunos e no apoio ao professor, de modo a desenvolver práticas que, por questões de tempo e de excesso de trabalho, os professores não oferecem aos alunos, mantendo-se, muitas vezes, como transmissor de saberes através da exploração teórica dentro da sala de aula.

Bizzo (2008, p. 136) conta que "levar o aluno a aprender a aprender é, de certa forma, a tarefa mais importante da escola". Então, o PIBID vem para mudar este cenário, oferecendo alternativas de ensino aos alunos, principalmente atividades práticas. Isto facilita o trabalho do professor e em muito melhora o interesse dos estudantes que já se encontram entediados pelas metodologias tradicionais, marcadas por aulas apenas expositivas.

Como salienta Neto et al., (2016, p. 2749):

O PIBID é uma "válvula de escape", pois o programa surge com ideias de inovação, de criações de estratégias que consigam reverter o quadro de rejeição por parte dos alunos, sempre dando ênfase as aulas práticas, que para nós futuros professores são de grande contribuição na construção do conhecimento. 


\section{Considerações finais}

Com as experiências vividas e adquiridas pelos estudantes que passaram pelo Programa Institucional de Bolsas de Iniciação à Docência (PIBID), foi possível perceber a importância e a contribuição que ele proporcionou a todos os envolvidos. Este relato de experiência é mais do que uma simples descrição de aprendizado, é também uma exposição significativa do que o PIBID propiciou ao sistema educacional. Todas as atividades descritas no texto foram essenciais para contribuição da formação acadêmica de cada estudante enquadrado no projeto, como também para a escola inserida que pode desfrutar de um ensino dinâmico e interdisciplinar.

Com este modelo de ensino, os alunos das escolas puderam ampliar os conhecimentos compartilhados em sala de aula para abranger toda uma sociedade, pois o PIBID aproximou a teoria vista no ensino básico da realidade que o aluno vivencia no cotidiano, podendo, assim, debater com senso crítico sobre o elo de suas experiências com os conceitos vistos nas disciplinas.

Pelos relatos aqui descritos, o PIBID oportunizou a escola o desenvolvimento de várias atividades pedagógicas, com ênfase na Educação Ambiental, sensibilizando e conscientizando os alunos da realidade dos problemas ambientais que eles estão inseridos, de modo que estas práticas tiveram resultados favoráveis, pois além das abordagens, intervenções foram executadas, buscando amenizar os problemas que os cercam.

Estas atividades refletiram de forma positiva não só nas discentes em formação, como também na escola, pois auxiliaram os professores, trazendo novas alternativas de ensino com práticas interdisciplinares que se tornaram mais ativas no processo de construção do conhecimento, melhorando sua desenvoltura e aprimorando suas habilidades nos espaços da academia e da escola.

\section{Referências}

ALARCON, A.M.Y.; BERVIAN, P.V. Iniciação à docência em Ciências e Biologia: implicações na Educação Ambiental. In.: Anais do IV CIECITEC, Santo Ângelo-RS, p. 9, 2017.

BIZZO, N. Ciências: Fácil ou difícil?.2. ed. São Paulo: Ática, 2008.

BRAGA, R.A.; LIMA, A.G.S. A relação da educação ambiental com as aulas de campo e o conteúdo de biologia no ensino médio. Revista Eletrônica em Gestão, Educação e Tecnologia Ambiental-REGET, v.18 n.4, p.1345-1350, 2014.

CÂMARA, J.F.O.R.; ARAÚJO LIMA, V.T. A utilização de vídeo e trilha como instrumentos de educomunicação na APA da UFAM. Revista Brasileira de Educação Ambiental (RevBEA), v. 12, n. 2, p. 79-95, 2017. 
DEUS, T.R.V.; PIMENTEL, A.S.P.; SOUZA, A.P.R.; RAMOS, P.R.R. Educação ambiental nas escolas: Arborização do colégio estadual Rui Barbosa, JuazeiroBA. In.: Anais do $\mathrm{V}$ Congresso Brasileiro de Gestão Ambiental. Belo Horizonte/MG, 2014.

DINIZ, L.S.; SILVA, I.N.; DUARTE, J.D. As contribuições do Pibid na formação dos discentes do curso de licenciatura plena em química do CFP/UFCG campus de Cajazeiras-PB. Revista de Pesquisa Interdisciplinar, Cajazeiras, v. 1, Ed. Especial, p. 153 -159, 2016.

EISENLOHR, P. V. et al. Trilhas e seu papel ecológico: o que temos aprendido e quais as perspectivas para a restauração de ecossistemas? Hoehnea v.40, n.3, p. 407-418, 2013.

FREITAS FILHO, J. R. et al. Ensinagem com Projetos: Ferramenta Combinada com outras Estratégias de Ensino Utilizada em Aulas de Química Biológica. Revista Experiências em Ensino de Ciências, v. 10, n. 3, 2015.

GALDINO, J. S. Lagoa Urbana de Cuité-PB:Uso e degradação, aspectos históricos contribuintes para a poluição narrados por moradores. Monografia (Curso de Licenciatura em Ciências Biológicas) - Centro de Educação e Saúde/UFCG, 54p., 2014.

GONZAGA, G. R. et al. Jogos didáticos para o ensino de Ciências. Revista Educação Pública, v. 17, n. 7, 2017.

HARDOIN, R.L.A.; SILVA, T.L.; CHAVES, I.M.B. Narrativas de formação docente no prodocência e no Pibid. Revista@mbienteeducação, v. 10, n. 1, p.74-84, 2017.

MACHADO, M.G.; ABILIO, F.J.P. Educação Ambiental no Bioma Caatinga: A utilização de modalidades didáticas inovacionais na realização de vivências eco pedagógicas. In.: Anais do XIII Congresso Internacional de Tecnologia na Educação, p. 17, 2015.

MELO, R.A.M.A.; CARVALHO, A.D.F. Educação Ambiental no Programa Institucional de Bolsas de Iniciação à Docência: trabalho colaborativo entre universidade e escola pública no interior da Bahia (Sorocaba/SP), v.3, n.2 Especial, p. 465-478, 2017.

MMA. Ministério do Meio Ambiente. Lixo um grave problema no mundo moderno. Disponível em: <http://www.mma.gov.br/estruturas/secex consumo/ arquivos/8\%20-\%20mcs lixo.pdf>.Acesso em: 18.03.2018.

NETO, A.C.B.; SILVA, J.C.C.; NASCIMENTO, L.Q.; OLIVEIRA, R.L. Atuação dos bolsistas do Pibid na Escola Estadual Professora Clara Tetéo - Macau/RN: a importância do Pibid para a realização de atividades práticas no ensino de biologia. Revista da SBEnBio, n. 9, p. 2746- 2755, 2016. 
SILVA, S.C. et al. Micro estufa sustentável uma alternativa reciclável para a produção de hortaliças. In.: Anais- VIII Mostra de Iniciação Cientifica, Tecnológica Interdisciplinar. IFSC. 2015.

SILVA, S.M.; NUNES, C.P. O Pibid como política pública de formação de professores. Educação em Debate, Fortaleza, ano 38, n. 72, p. 89-103, 2016.

SILVA, S.N.; CARVALHO, G. Educação Ambiental no Programa Institucional de Bolsas de Iniciação à Docência: trabalho colaborativo entre universidade e escola pública no interior da Bahia. Saberes em perspectiva, Jequié, v.5, n.12, p. 7-26, 2015.

SILVA. E.F.; PAVINATO, J.M.S.; SAVI, D.; AHLERT, A. Atividade de campo no Ensino Superior: um estudo de caso etnográfico. Revista Brasileira de Educação Ambiental (RevBEA), São Paulo, v. 12, n. 5, p. 26-40, 2017.

VERASZTO, E.V.; PELLEGRINI, M.; RINZO, T.; RODRIGUES, T.G.; TEODORO, T.G.; BERTAGLIA, A.B. Impactos do PIBID na formação de licenciandos: avaliação de bolsistas egressos dos cursos de Licenciatura em Física, Química e Ciências Biológicas. Crítica Educativa (Sorocaba/SP), v. 3, n. 2 - Especial, p. 544-560, 2017.

VICENTE, C.P. PIBID-Biologia - resumo de nossa trajetória 2014-2017. In: AYOB, W.; PRADO, G.V.T.; PRODOCIMO, E. Aprendizados e desafios na formação de professores. Campinas, SP: Edições Leitura Crítica, p. 224, 2017. 